East African Medical Journal Vol. 80 No. 6 June 2003

NOISE INDUCED HEARING LOSS AMONG INDUSTRIAL WORKERS IN DAR ES SALAAM

B M. Minja MBChB (EA), MMed (Surgery) MSc (ORL), N.H. Moshi, MD, MMed (Surgery) MSc (ORL), Department of Otorhinolaryngology, Muhimbili University, College of Health Sciences, P.O. Box 65001 Dar es Salaam, Tanzania. P. Riwa, MD, MMed, Ministry of Labour, Dar es Salaam, Tanzania

Request for reprints to: Dr. N.H. Moshi, Muhimbili National Hospital, P.O. Box 65001, Dar es Salaam, Tanzania

\title{
NOISE INDUCED HEARING LOSS AMONG INDUSTRIAL WORKERS IN DAR ES SALAAM
}

\author{
B.M. MINJA, N.H. MOSHI and P. RIWA
}

\begin{abstract}
Objectives: To determine whether sound in the study areas was of sufficient intensity to cause hearing loss and if so whether those exposed have been affected and to determine whether workers/employees in the study areas were aware that sound can cause hearing loss and if so whether they knew that this can be prevented by ear protection.

Design: Cross-sectional study

Setting: Industrial area $A$ and $B$ randomly selected from among industries in Dar es Salaam.

Subjects: One hundred and fifty workers from area $A$ and fifty two employees from area $B$.

Results: In both study areas the noise levels were above the safe limit of $85 \mathrm{~dB}(\mathrm{~A})$. In area $A 28$ workers and in area $B$ eight employees had noise induced hearing loss. In area $A 1.1 \%$ of the workers and in area $B$ 85\% of the employees knew that noise causes hearing loss. All workers/employees from both study areas knew that noise induced hearing loss could be prevented by some form of ear protection.

Conclusion: Workers/Employees exposed to noise above $85 \mathrm{~dB}(\mathrm{~A})$ will eventually develop hearing loss. Workers/employees are aware of this hazard. There is therefore a need to educate those exposed on how best to protect their ears from the hazard and provide them with protective gear.
\end{abstract}

\section{INTRODUCTION}

The global prevalence of disabling hearing impairment is estimated to be $2.2 \%$. Tanzania with a population of approximately $30,000,000$ is expected to have 660,000 people with disabling hearing impairment. This assumes, of course, that preventable causes of hearing impairment including ear infections, infectious viral diseases such as mumps, measles and rubella among others are controlled at the same level as in the developed countries of the World(1).

Noisy environments are hazardous to the hearing. It is now well established that exposure to noise of sufficient intensity and duration damages the hearing of those exposed. Sound levels of less than $75 \mathrm{~dB}(\mathrm{~A})$ are unlikely to cause damage to hearing. However, sound levels of $85 \mathrm{~dB}(\mathrm{~A})$ and above for durations of eight hours per day causes damage to the hearing after many years of exposure(2).

The damage to hearing occurs at the level of the cochlear and therefore sensory in nature. In the initial stages, derangement of the hair cells takes place and this leads to temporary threshold shift (TTS). With prolonged exposure permanent damage to the hair cells takes place leading to permanent threshold shift (PTS). While TTS is reversible with withdrawal of the affected person from the hazardous noisy environment, PTS is irreversible.

The frequency centred around the $4000 \mathrm{~Hz}$ is the one initially involved despite the spectra and temporal characteristics of the noiser(3). Following this, continued exposure leads to involvement of the higher frequencies giving the typical down slop audiogram.

Noise induced hearing loss is among the top three causes of hearing impairment in Africa(4). This hearing loss is acquired at industrial or social level. Audiological screening of industrial workers in a textile factory in Dar es Salaam has shown that $25 \%$ of the employees exposed to the noise for eight hours of work daily for a period of over five years were found to have permanent threshold shift on pure tone audiometry. The noise level was persistently above $85 \mathrm{~dB}(\mathrm{~A})$.

This study was designed to answer the following questions:

(i) Is noise in the study area of enough intensity to cause damage to hearing?

(ii) If the noise intensity in the study area is higher than $85 \mathrm{~dB}(\mathrm{~A})$ has it affected those exposed?

(iii) Are the workers/employees in their respective industry aware that noise can damage their hearing?

(iv) If the workers/employees are aware that noise can damage their hearing are they using ear protectors? 


\section{MATERIALS AND METHODS}

Two study areas A and B were randomly selected from among the industries in Dar es Salaam.

Study area A: This industrial area is situated in the center of the Dar es Salaam city. The area covered by this is approximately quarter of a square kilometer and the activities taking place in the open include metal fabrication, black smithery, carpentry and tailoring of motor vehicle accessories. Within the same area, there are small shops for marketing the products. The activities involve hammering metal, welding, wood joinery and saw milling as well as grinding of grain.

The whole area was divided into 140 sections as shown on diagram I. In each of the sections, mixed activities including woodworks, hammering of metal and joinery of furniture takes place. The activities are carried out by the various owners of the industries and these industrialists work for ten to twelve hours per day depending on the demand. An apprenticeship take place at almost all places whereby primary school leavers are engaged to have on the job training by their parents or friends so that they can eventually earn a living. Unlike engagement in offices, these people depend wholly on their sweat for survival. They are therefore very committed to their work. Medical examination is not a requirement for engagement in the respective industry/apprenticeship.

Study area B: This is situated in the industrial area of Dar es Salaam. It is organized into twelve sections. Section 1 accommodates offices, a plate section and a store. Sections 23 and 4 accommodate all the printing machines. Sections 5,6 , and 7 accommodate machines for the manufacture of crown corks, batteries and crates. Sections $8,9,10$ and 11 is where smag. press and tin (debe) manufacturing activities take place. Sections 12 and 13 are for engineering works. In all these sections there is noise the intensity of which is commensurate with the activities taking place at the particular moment. Manufacturing takes place during the day and night in shifts of eight hours each.

Noise measurement in the study areas: In both industrial settings noise was measured using Integrating Sound Level Meter Type 2225 (Briiel \& Kjaer) and Sound Level Calibrator
Model 5274 at $1 \mathrm{KHz} 94 \mathrm{~dB}$. This work was done by a technician well trained in industrial safety from the Ministry of Labour. At each of the sections, two measurements were made; one during the peak of activities and another when there were no activities taking place. The noise levels were recorded for each of the sections.

Data collection on the exposed workers/employees: A questionnaire was designed for collecting information on all the employees/workers. The information sought included age, sex, occupation, duration of employment in the present job, number of continuous working hours per day, previous employment in a different factory or section, nature of work and duration of engagement.

Medical history of the worker/employee focused on previous ear discharge, mumps, measles, use of ototoxic drug including streptomycin and quinine, exposure to explosions and discotheque music, previous head injury or involvement in motor traffic accident.

Besides, the worker/employee was questioned regarding inability to hear clearly in a crowd, trouble in hearing the telephone, and need to ask people to repeat statements. Knowledge on harmful effects of excessive noise and the need to protect oneself was also assessed. All workers/employees had ear examination and the findings recorded. Pure tonc audiometry was carried out on all the subjects in the morning before they stated work and having been out of the factory/ work place for sixteen hours or more.

The data collected was then processed and the results computer analysed.

\section{RESULTS}

Noise levels in the work place: Analyses of the noise levels (dBA) in the various sections of area $A$ according to the shed and activity taking place. The minimum peak noise level was $87 \mathrm{dBA}$ and the maximum was $116.5 \mathrm{dBA}$. The average noise level in this open area was $92.6 \mathrm{dBA}$. As expected. maximum noise levels were recorded in the areas with hammering activities taking place. Offices had the least recorded noise levels (Table 1).

Table 1

Noise level measurement: Area $B$; metal box industry

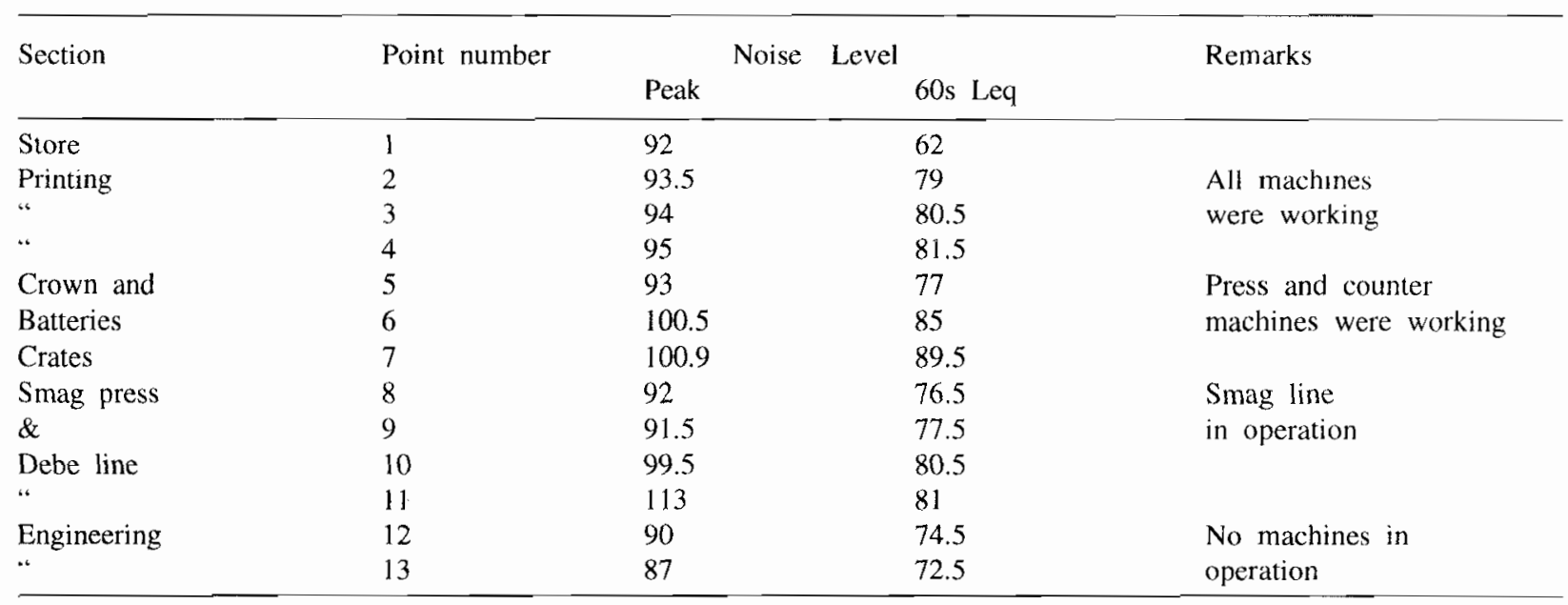


Table 2 analyses the noise levels in the various working sections of Study Area B. As shown, the minimum noise level recorded was $87 \mathrm{~dB}(\mathrm{~A})$ and the maximum was $11 \mathrm{MBA}$. While in all sections of the factory the noise levels recorded were significantly above the recommended safe noise levels, the Crown and Batteries Case section had the highest noise level.

These results therefore have shown that in both industrial settings, the noise levels were higher than the safe limit of 85dBA and therefore hazardous to those exposed for prolonged periods of time.

Table 2

Noise level measurement: Area A

\begin{tabular}{ll}
\hline $\begin{array}{l}\text { Type of } \\
\text { activity Shed(s) }\end{array}$ & Noise levels \\
\cline { 2 - 2 } & Peak 60s Leq \\
\hline
\end{tabular}

\section{Metal}

works

\begin{tabular}{|lll}
1 to 10 & 104.5 & 75 \\
11 to 20 & 105 & 71.3 \\
21 to 30 & 116.5 & 86.8 \\
31 to 40 & 111.8 & 84.1 \\
41 to 50 & 112.5 & 83.7
\end{tabular}

Hammering in
some shade
Other not operating

41 to $50 \quad 112.5 \quad 83.7$

Woodworks

$\begin{array}{llll}51 \text { to } 60 & 93 & 76.1 \\ 61 \text { to } 70 & 96.9 & 74.6 \\ 71 \text { to } 80 & 91.1 & 68.8 \\ 81 \text { to } 90 & 94.6 & 68.1 \\ 91 \text { to } 100 & 98.7 & 71 \\ 101 \text { to } 110 & 92.4 & 71.4 \\ 111 \text { to } 120 & 87 & 69.4 \\ 121 \text { to } 130 & 98.2 & 79.7 \\ 131 \text { to } 140 & 96.4 & 73\end{array}$

\section{Effect of the noise on those exposed}

Area A employees: A total of 140 area A employees were investigated. Of these, complete data was available on 124. The remaining 16 could not be available for pure tone audiometry because they had changed their working place and could not be traced. These were not considered in the data analysis.

Among those who had the investigation completed, $61(49.2 \%)$ were found to have normal hearing. Sixty three $(50.8 \%)$ were found to have audiogram patterns typical of noise induced hearing loss.

Among the employees with noise induced hearing loss $35(28.2 \%)$ had temporary threshold shift at $4000 \mathrm{~Hz}$. Their ages ranged from 19 to 68 years, had been exposed to the noise hazard for periods ranging from 1 to 31 years. The dip at $4000 \mathrm{~Hz}$ ranged from 40 to $70 \mathrm{~dB}$ HL. The majority of those affected $(80 \%)$ were engaged in metal fabrication activities while the rest $(20 \%)$ were carpenters.

There were $28(22.5 \%)$ employees whose pure tone audiogram patterns were typical of permanent threshold shift. These were aged between 17 and 58 years, had been engaged on their respective jobs for 1 to 31 years, their hearing loss at $8000 \mathrm{~Hz}$ ranged from 50 to $80 \mathrm{~dB}$ HL of these $82 \%$ were involved in metal fabrication while the remaining $18 \%$ were carpenters.

Area B employees: Fifty two employees were investigated. Among these, $43(82 \%)$ completed the study and the remaining nine (18\%) could not be available for audiometry because they had changed employers or had their services terminated.

Among those who completed the study, 20 (46.5\%) had noise induced hearing loss. The affected employees were aged from 28 to 60 years and had been exposed to the industrial noise for periods ranging from 8 to 29 years.

Regarding those with noise induced hearing loss, $12(27.9 \%)$ had audiograms with dips at $4000 \mathrm{~Hz}$ ranging from 40 to $55 \mathrm{~dB} \mathrm{HL}$ consistent with temporary threshold shift.

In this category of employees, seven $(58 \%)$ were machine operators, two were technicians and the remaining were supervisors, feeders and line setters respectively. Permanent threshold shift was recorded in eight $(18.6 \%)$ of the employees with noise induced hearing loss. In this category, three were machine operators, two filter turners, 21 were engaged in printing and one was a line setter. Their ages ranged from 31 to 55 years and had been exposed to the noise hazard for periods ranging from 11 to 26 years. The hearing loss in this group was up to $70 \mathrm{~dB} \mathrm{HL}$ at 8000 $\mathrm{Hz}$ at the time the examination was done.

Do those exposed know that noise can harm their hearing?: Knowledge about the harmful effects of noise among the area $\mathrm{A}$ workers was as shown on Table 3. The majority of the workers $(81.1 \%)$ responded that noise causes hearing impairment. The remaining gave various responses ranging from palpitations $(6.2 \%)$, ringing in the ears $(4.2 \%)$ drum perforation, increased blood pressure and even annoyance.

Table 3

Response to the question on effect of noise on hearing by area $A$ workers

\begin{tabular}{lcc}
\hline Response & Frequency & $\%$ \\
\hline Hearing loss & 77 & 81.1 \\
Palpitations & 6 & 6.3 \\
Ringing in the ears & 4 & 4.2 \\
Headache & 3 & 3.2 \\
Annoyance & 1 & 1.1 \\
Increased BP & 1 & 1.1 \\
Pain in the ears & 1 & 1.1 \\
Drum perforation & 1 & 1.1 \\
Can't explain & 1 & 1.1 \\
\hline
\end{tabular}


Table 4 analyses the responses by the area $B$ workers to the same question. Eighty five per cent of the workers responded that noise causes hearing loss. The remaining had various responses such as noise causes disturbance, harm to the ear drum membrane, hypertension and even ulceration of the ears.

Table 4

Response to the question on effect of noise on hearing by area $B$ employees

\begin{tabular}{lcc}
\hline Response & Frequency & $\%$ \\
\hline Hearing loss & 33 & 87.0 \\
Disturbance & 1 & 2.6 \\
Drum rupture & 1 & 2.6 \\
Harms drum & 1 & 2.6 \\
Causes hypertension & 1 & 2.6 \\
Ulceration of the ears & 1 & 2.6 \\
\hline Total & 38 & 100 \\
\hline
\end{tabular}

Do those who know that noise can harm their hearing know how to protect themselves: Tables 5 and 6 analyse the responses of area $A$ and $B$ workers to this question respectively. In both groups they know how to protect themselves from the harmful effects of noise. While $91 \%$ of the area B employees know specifically that ear plugs are useful in protecting themselves from noise damage to their hearing, only $6.7 \%$ of the area A workers know this. However all know that some form of protection is necessary or useful. It will be noted that area $\mathrm{B}$ employees have a better educational background than the area A workers.

\section{Table 5}

Response to the question on how to protect oneself from the effects of noise by area $A$ workers

\begin{tabular}{lcc}
\hline Type of protective gear & Frequency & $\%$ \\
\hline Ear muffs & 21 & 46.7 \\
Ear protection & 19 & 42.2 \\
Ear plugs & 3 & 6.7 \\
Cotton wool plugs & 2 & 4.4 \\
\hline Total & 45 & 100 \\
\hline
\end{tabular}

Table 6

Response to the question on how to protect oneself from the effects of noise by the area $B$ employees

\begin{tabular}{lcc}
\hline Type of protective gear & Frequency & $\%$ \\
\hline Ear plugs & 32 & 91 \\
Protection & 2 & 6 \\
Ear muffs & 1 & 3 \\
\hline Total & 35 & 100 \\
\hline
\end{tabular}

\section{DISCUSSION}

It is quite clear from the results that in both industrial settings, the noise level was above the $85 \mathrm{~dB}$ A level and therefore hazardous to the hearing of those exposed. On the average, the noise level at area $\mathrm{A}$ was $92.6 \mathrm{dBA}$ while that at area $\mathrm{B}$ was $100 \mathrm{dBA}$.

Indeed the effect of the noise on the employees in both industrial settings was quite significant and correlates well with the findings following examination of those exposed. Among the area A workers, 28.2\% and $22.5 \%$ had temporary and permanent threshold shift respectively. Similar results were observed on the area B employees of whom $27.9 \%$ and $18.6 \%$ had temporary and permanent threshold shifts respectively. As expected, those engaged in metal fabrication and operating machines were the worst affected when compared to those engaged in carpentry and other jobs.

It was gratifying to note that the majority of the employees in both industrial settings recognised that noise was harmful to their hearing. Of the area $A$ employees, $79 \%$ knew that excessive noise causes hearing impairment. Similarly $85 \%$ of the area B employees knew that noise causes hearing loss. However, while $91 \%$ of the area B employees specifically knew that ear plugs were useful in protecting themselves from the harmful effects of noise, only $6.7 \%$ of the area $\mathrm{A}$ workers knew this. The only explanation for this difference is their respective educational background. area $B$ employees are secondary school leavers while the area A workers are mostly primary school leavers or have not been to school.

The fact that the workers in both industrial settings recognise that noise causes harm to their hearing renders opportunity for intervention. Well informed of the means at hand to protect themselves, the risk to their hearing can be greatly reduced. Therefore there is need to educate workers engaged in noisy environments on the risk to their hearing and how to protect themselves. Along with this, such workers should be routinely examined so that those who develop temporary threshold shift can be detected early and withdrawn from the hazardous environment.

Apparently, employees in factories undergo medical examination before they are engaged. However, their hearing is not measured during the medical examination. This calls for serious consideration because among the employees there could be some with hearing loss before they are engaged. In this respect if eventually they claim for compensation it will be to the employer's disadvantage for these should have been identified before they are employed.

While medical examination is possible for those engaged in factories, the area A workers may not see the need for it. These workers are self employed and the majority are on the job training. It is therefore necessary to educate them on the risk of losing their hearing after long exposure as well as the available means of protecting themselves. 
Ideally, the noise in industries should be controlled within the safe limit of $85 \mathrm{dBA}$ and lower. In developing countries where the machines used are old and the economic situation is not permissive, replacement of the machines may not be possible. Therefore the most reasonable approach is to educate the workers on the need to protect themselves against noise in their respective work places.

In conclusion the noise level in area $A$ and area $B$ factory is above the safe limit of $85 \mathrm{dBA}$ and therefore hazardous to those exposed. In both industrial setting the noise had caused irreversible damage to $22.5 \%$ and $18.6 \%$ of area $\mathrm{A}$ and area $\mathrm{B}$ work force respectively. Unless withdrawn from the noise, the $50.8 \%$ and $46.5 \%$ of the area $A$ and area B factory workers respectively are at risk of developing irreversible damage to their hearing. Workers/employees in these setting are, on the majority, aware that noise damages their hearing and that this can be prevented by using some form of protective gear including ear plugs. There is therefore need to educate those exposed on how best to protect themselves from the noise hazard.

We recommend that before employees are engaged into factories they should have ear examination and audiometry done as part of the medical examination. Education on the hazardous effects of noise and how to protect oneself should be given to all employees in noisy factories. This should be a requirement for all employers with noisy factories. Through health education, the Ministry of health should educate the public on the harmfull effects of noise. Regular examination of employees/workers in noisy environments is necessary so that those with temporary threshold shift can be identified early and appropriate action taken well on time.

\section{ACKNOWLEDGEMENTS}

We extend our sincere gratitude to the general managers of area A and B industrial estates in Dar es Salaam for allowing us to conduct this study in their respective areas. We would also want to thank Mr. A. Jacob, clinical officer at the industrial areas for coordinating the examination of the workers and to Mr. A. Machemba for performing the audiometric tests.

\section{REFERENCES}

1. Report on The WHO Workshop on Prevention of Deafness and Hearing Impairment in Africa, Nairobi, Kenya. 1995; 10: $24-27$.

2. The National Institute of Health Consensus Development Conference on Noise and Hearing Loss: Consensus Statement. 1990; 8: 1-24, 22-24.

3. Pierso L.L.. Gerhardt, M. Rodriguez, G.P., Yanke, R.B. Relationship between outer ear resonance and permanent noise induced hearing loss: Amer. J. Otolaryngology. 1994; 15:37-40.

4. Report on the WHO Workshop on Prevention of Deafness and Hearing Impairment in Africa, Nairobi, Kenya. 1995; 10: $24-27$. 